\title{
Exposure to External Role Models as a Determinant of Entrepreneurial Culture in Southern Nigeria
}

\author{
Christabel Divine Brownson \\ Faculty of Social and Management Sciences \\ Akwa Ibom State University
}

\begin{abstract}
Research shows that providing role models could aid in the promotion of positive attitudes towards entrepreneurship. However, while a lot of emphasis has been on parental role models, limited research has focused on the influence of other forms of role models on individuals entrepreneurial decisions with paucity of data on the influence of subjective experience of role models in influencing individuals towards entrepreneurship. Studies have suggested that more than parental influences need to be considered in future research. It is in this regard that this paper investigates the influence of external role models in determining the development of Entrepreneurial Culture in Southern Nigeria. Using a descriptive study, 197 respondents who experienced the use of external role models were examined and findings reveal that the use of external role models other than parental role models does aid in nurturing entrepreneurial culture. The findings contribute new knowledge to the entrepreneurship literature in terms of the use of external role models other than parental role models in stimulating business startups.
\end{abstract}

Keywords: Role Models, Entrepreneurial Culture, Entrepreneurship, Attitudes, Entrepreneur, Behaviours, Intentions, Entrepreneurial Decision Making

\section{INTRODUCTION}

Role modeling occurs when social behaviour is informally observed and then adopted by a learner who has learned by example rather than by direct experience (Scherer et al., 1989). Scherer et al. (1989) using social learning theory asserted that one way learning can occur vicariously via the observation of behaviours in others, referred to as models. They pointed out that an individual observes the model engaging in various social behaviours and notes the reinforcements received by the model, if the observer values the reinforcements or recognizes the positive outcomes of such behaviour then, the observer will attempt to replicate the model's behaviour and obtain similar types of reinforcements. They indicated that entrepreneurial role model may appear in the guise of family members, employers, teachers or anyone who the individual has had the opportunity to observe. They further suggested that role models other than the parents may help explain the entrepreneurial career decisions of individuals without parental role. Noting further, they highlighted that subjective experience of role models, carried out through case studies, recommended readings, films, conferences and exploration of websites has a fundamental function in enabling an individual to envision a potential version of their becoming. As such, entrepreneurial role models allows individuals to materialize their visions of what they could, should or want to be in the form of desired identity images (Schlenker, 1985 cited in Scherer et al., 1989). Van Auken et al. (2006) indicated that while it is generally accepted that a role model is a key influence in a potential entrepreneur's decision making, limited research has investigated the impact of role models on desire to own a business. Mattew and Moser (1996) adds that role models from outside the family structure may actually be more critical as such, they suggest that more than parental 
influences need to be considered in future research. It is in this regard that this paper investigates the influence of external role models in determining the development of Entrepreneurial Culture in Southern Nigeria.

\section{ROLE MODELS AND ENTREPRENEURIAL CULTURE}

The promotion of Entrepreneurial Culture and positive attitudes towards entrepreneurship can be encouraged by providing role models through the show casing of success stories (Lafuente et al., 2007). Role models serves as motivational incentives with incremental or decremental effects on behaviour depending on what form the anticipating outcomes take for the observers (Radu and Loue, 2008). Role models help to develop the desire and confidence to create one's own business. It also modifies the cognitive perceptions of the agents in a way that can favour the agent's decision to undertake entrepreneurial activities actively (Lafuente et al., 2007). Radu and Loue (2008) posited that exposures to entrepreneurial role models provides invaluable information, inspires confidence and stimulates observers to elaborate anticipatory scenarios of their own future career and identity. Accordingly, Vaillant and Lafuente (2007) stated that the presence of entrepreneurial role models be it in a rural or urban setting strongly influences the cognitive representations of economic agents and strongly influences the decision to become an entrepreneur.

Radu and Loue (2008) explained that vicarious learning encourages observers to rely on role models exemplified behaviour but that the importance of vicarious role models such as entrepreneurs' testimonials and narratives seems to remain underestimated, while its actual effects on motivation and action are yet to be more deeply examined. Exposure to role models has been shown to have a demonstration effect on others (Lundstrom and Stevenson, 2005). Vaillant and Lafuente (2007) stated that positive examples strongly influence an individual's decision to become an entrepreneur. They found significant relationship between role model and entrepreneurial activity in rural areas.

Carter et al. (2002) found a minimal influence of role models on nascent entrepreneur's career choice. Lafuente et al. (2007) found that the presence of role models exerts a positive and statistically significant impact upon an individual's entrepreneurial intentions which is similar to BarNir et al,'s (2011) findings. Krueger (1993) found a positive relationship between positiveness of the role model experience and perceived desirability of founding a firm. Davidsson's (1995) research on entrepreneurial intentions indicated that the perception of the role model on a 'very negative' to 'very positive' scale was a very strong predictor of the intention score.

Scott and Twomey (1988) reported a link between parent role and the preference for self employment. Cooper (1986) found evidence that firm founders were influenced by role models in their decision to become entrepreneurs. Van Auken et al. (2006) found that role model activities related to involving the respondent in professional activities, employment in the business and discussion about the business were found to be significantly related with interest in starting a business. However, the focus in this study is not parental role model but external role models (role models outside the family structure) used by the government agencies in the form of guest speakers and mentors in events via the media in the delivery of the entrepreneurship promotion policy.

\section{METHODS}

Using purposive sampling method with a structured questionnaire, data was collected from 195 respondents who participated in entrepreneurship programmes from governmental 
sources in Akwa Ibom one of the Southern State in Nigeria. Descriptive statistics was used to analyze the data.

\section{ANALYSIS}

The analysis revealed that exposure to external role models did contribute to the development of entrepreneurial culture as shown in the slightly high percentage of respondents who agreed to its impact on their Entrepreneurial Attributes (EA - 69\%), Values (EV -74\%), Mindset (MDS 73\%), Intention (INTENTN - 81\%) and their Entrepreneurial Behaviour (ENTRBEHAV - 71\%) compared to those who disagreed as shown on fig. 1below. The respondents (95\%) also found the use of the role models by the government agencies useful. This implies that the contact the respondents had with the role models used by the government agencies as well as their perception of the role models' performances did aid in the development of their entrepreneurial culture in the context studied.

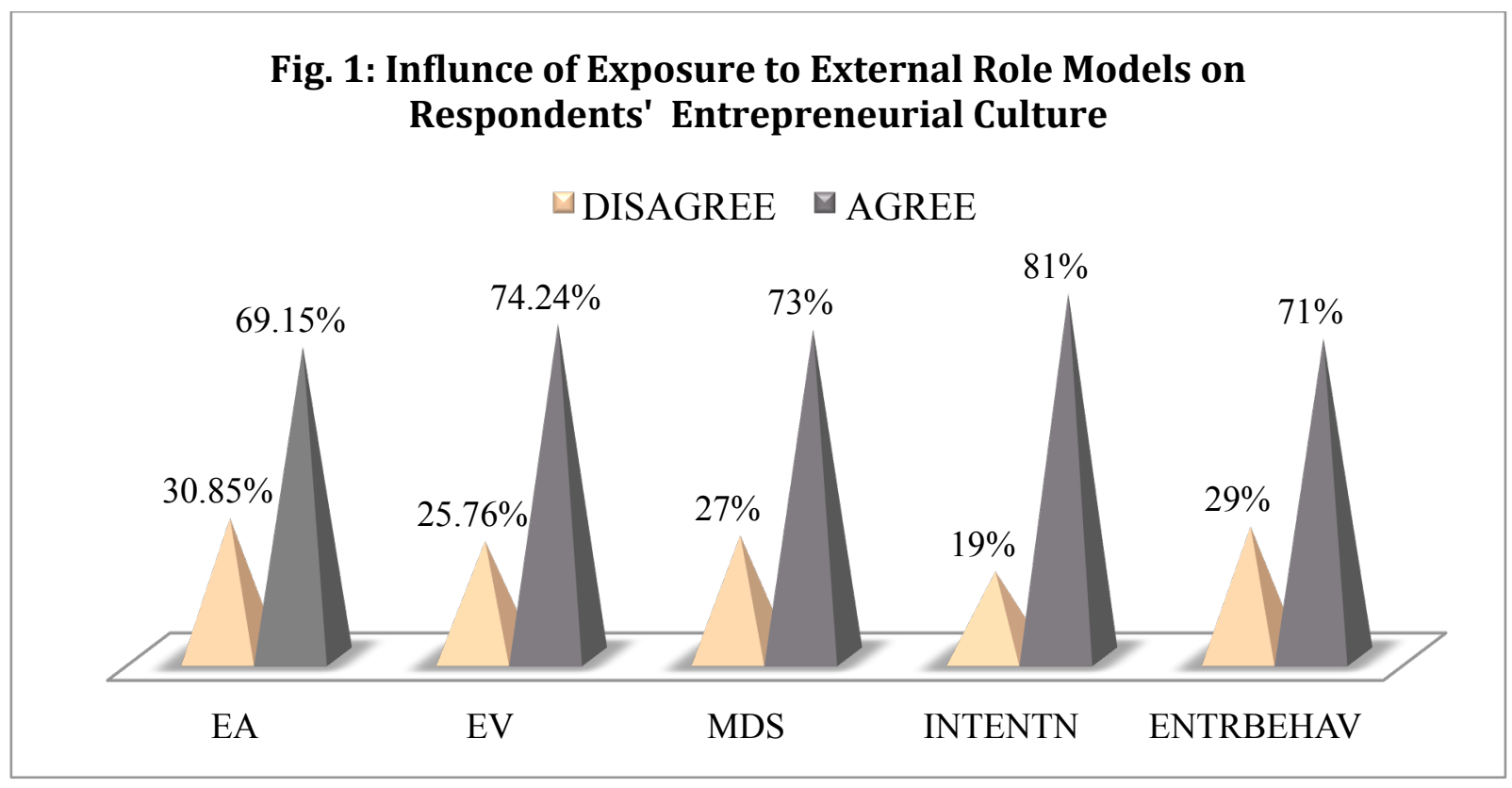

\section{DISCUSSION OF FINDINGS}

The descriptive analysis indicated support that Exposing people to external role models other than parental role models does influence the development of entrepreneurial culture. The descriptive analysis suggests that Exposure to External Role Models provided by the government agencies does contribute to the development of the EA, EV, MDS, INTENTN and ENTRBEHAV of the participants of the entrepreneurship policy measures. This suggests that exposure to external role models did nurture all the constituent of entrepreneurial culture to enhance the level of entrepreneurship in the state so as to reduce the dependency on civil service jobs and unemployment in the state during the period under study.

These analyses contributes new knowledge to the entrepreneurship literature by addressing the gap in the literature advocated by Mattew and Moser (1996), Scherer et al. (1989) and Radu and Loue (2008) that more than parental influences and vicarious role models should be examined. The findings of the contribution of Exposure to External Role Models on the participants' EA and EV is a new knowledge contribution to the literature which will require further research to investigate this linkage as limited study have actually examined such links. The findings however agrees with Radu and Loue (2008) and Lafuente et al. (2007) postulations that role models serve as motivational incentives which inspires the observers' confidence towards the creation of their own business. 
The findings that Exposure to External Role models influences the MDS of the participants aligns with Lafuente et al. (2007) and Vaillant and Lafuente's (2007) assertions that entrepreneurial role models strongly influences the perceptions of the agents in a way that can favour the agent's decision to undertake entrepreneurial activities. The finding also agrees with Scott and Twomey (1988) that role models have a link with preference for selfemployment. The descriptive findings that Exposure to External Role models slightly contribute to the development of the participants' INTENTN and ENTRBEHAV supports prior research by Van Auken et al. (2006), Davidsson's (1995), Lafuente et al. (2007) BarNir et al.'s (2011) and Carter et al.'s (2007) on the influence of role models on intention as well as previous research by Cooper (1986) who found evidence of firm founders being influence by role models in their decision to become entrepreneurs.

\section{CONCLUSION}

This paper sought to investigate the influence of external role models in determining the development of Entrepreneurial Culture in Southern Nigeria Through the descriptive analysis used, it can be concluded that external role models other than parental role models does to some extend contribute in determining the development of Entrepreneurial Culture in Southern Nigeria.

\section{References}

BarNir, A., Watson, W. and Hutchins, H. (2011) Mediation and Moderated Mediation in the Relationship Among Role Models, Self-Efficacy, Entrepreneurial Career Intention, and Gender, Journal of Applied Social Psychology, February 2011, Vol. 41, Issues 2 p270-297, 28p

Brownson, C. D. (2014) Nurturing Entrepreneurial Culture: Analysis on Akwa Ibom, Lambert Academic Publishing, LAP, Germany (October, 2014) ISBN: 978-3-659-59133-4.

Carter, N. M.; Gartner, W. B. and Greene, P. G. (2002) The Career Reasons Of Minority Nascent Entrepreneurs, Academy of Management Proceedings \& Membership Directory, 2002, pD1-D6, 6p

Cooper, A. (1986). "Entrepreneurship and High Technology," The Art and Science of Entrepreneurship, Ed. D. Sexton and R. Smilor, Cambridge, Mass.: Ballinger Publishing Company, 153-180.

Davidsson, P. (1995) Determinants of Entrepreneurial Intentions, paper prepared for the RENT IX Workshop, Piacenza, Italy, November, 23-24, 1995

Krueger, N. (1993) The Impact of Prior Entrepreneurial Exposure on Perceptions of New Venture Feasibility and Desirability, Entrepreneurship: Theory \& Practice, Fall93, Vol. 18 Issue 1, p5-21, 17p,

Lafuente, E., Vaillant, Y. and Rialp, J. (2007) Regional Differences in the Influence of Role Models: Comparing the Entrepreneurial Process of Rural Catalonia, Regional Studies, Aug2007, Vol. 41 Issue 6, p779-796, 18p

Lundström, A. and Stevenson, L. (2005) Entrepreneurship Policy: Theory and Practice, New York: Springer, c2005

Matthews, Charles H.; Moser, Steven B. (1996) A Longitudinal Investigation of the Impact of Family Background and Gender on Interest in Small Firm Ownership, Journal of Small Business Management, Apr96, Vol. 34 Issue 2, p29-43, 15p

Radu, M. and Loué, C. (2008) Motivational Impact of Role Models as Moderated by "Ideal" vs. "Ought Self-guides" Identifications, Journal of Enterprising Culture, Dec2008, Vol. 16 Issue 4, p441-465, 25p

Scherer, R. F.; Adams, J. S.; Carley, S. S. and Wiebe, F. A. (1989) Role Model Performance Effects on Development of Entrepreneurial Career Preference, Entrepreneurship: Theory \& Practice, Spring89, Vol. 13 Issue 3, p53-71, 19p

Scott, M.G., and Twomey, D.E (1988) "The Long Term Supply of Entrepreneurs: Students' Career Aspirations in Relation to Entrepreneurship," Journal of Small Business Management (October), 5-13.

Van Auken, H., Fry, F. and Stephens, P. (2006) The Influence of Role Models on Entrepreneurial Intentions, Journal of Developmental Entrepreneurship, Jun2006, Vol. 11 Issue 2, p157-167,11p 